\title{
DESAIN MODUL PERTANIAN VERTIKAL KOTA UNTUK PROYEK EDU AGROWISATA
}

\author{
Indi Andani ${ }^{1)}$, Priscilla Epifania Ariaji ${ }^{2)}$ \\ ${ }^{1)}$ Program Studi S1 Arsitektur, Fakultas Teknik, Universitas Tarumanagara, indi.andani2@gmail.com \\ 2) Program Studi S1 Arsitektur, Fakultas Teknik, Universitas Tarumanagara, priscillae@ft.untar.ac.id
}

\begin{abstract}
Abstrak
Sebuah pertanian vertikal mempunyai berbagai macam kebutuhan, salah satunya adalah rak tanaman yang akan diterapkan di dalamnya. Tentu sebuah rak tanaman juga memiliki ukuran yang berbeda - beda tergantung dengan jenisnya. Jika kebutuhan luas ruang rak dan modul bangunan tidak direncanakan terlebih dahulu, maka desain bangunan akan menjadi berantakan. Oleh karena itu, desain modul pertanian vertikal untuk edu agrowisata itu penting. Hal tersebut diawali dengan melakukan analisis jenis tanaman yang akan tanam, lalu menganalisis jenis hidroponik yang cocok digunakan untuk tanaman tersebut, setelah itu mencari tahu rak tanaman apa yang paling efisien untuk digunakan. Rak - rak tanaman tersebut mempunyai ukuran lebar, panjang dan tinggi yang berbeda beda. Maka dari itu, perlu adanya analisis mengenai besaran rak yang akan diterapkan di dalam bangunan untuk mencapai luasan yang efektif. Setelah mengetahui besaran rak dan kebutuhan - kebutuhannya, terbentuklah luasan desain modul yang diperlukan dalam bangunan pertanian vertikal untuk edu agrowisata.
\end{abstract}

Kata kunci Agrowisata, Desain Modul, Pertanian Vertikal

\begin{abstract}
A vertical farm has a variety of needs, one of which is a plant rack that will be applied in it. Of course, a plant rack also has different sizes depending on the type. If the extensive shelf space requirements and building modules are not planned in advance, the building design will not be efficient and there will be lots of wasted space. Therefore, the design of vertical farming modules for edu agrotourism is important. This begins by analyzing the types of plants that will be planted, then analyzes the types of hydroponics that are suitable for the plant, and then the result will show that which racks are the most efficient to use. The shelves of these plants have different widths, lengths and heights. Therefore, it is necessary to analyze the size of the racks that can be applied in the building to fullfil the most effective area. After knowing the size of the shelves and their needs, an area of module design is needed in vertical farm buildings for edu agrowsiata.
\end{abstract}

Keywords Agro-tourism, Module Design, Vertical Farming

\section{PENDAHULUAN}

\section{Latar Belakang}

Untuk mencapai desain yang maksimal, perlu adanya desain modul agar keperluan ruang dan sirkulasi dapat mencapai kebutuhannya masing - masing dengan perhitungan yang efisien. Dalam bangunan pertanian vertikal, ada rak - rak tanaman dengan berbagai macam ukuran yang memerlukan luasan tertentu untuk penempatan rak itu sendiri maupun kebutuhan ruang untuk panen. Selain itu, untuk mengetahui kebutuhan luas ruang sebuah rak perlu adanya analisis kegiatan yang terjadi pada rak tersebut.

Setelah menganalisis dan mengetahui kebutuhannya terbentuk luasan yang diperlukan dari sebuah rak. Dengan demikian, setelah mengetahui luasannya, dapat terbentuk luasan untuk modul bangunan. Maka dari itu, terbentuklah perhitungan luasan dan dapat terbentuk pula luasan modul yang tepat untuk desain bangunan tersebut. Hal ini mendukung terbentuknya bangunan dengan modul yang tepat dan efisien. 


\section{Tujuan Penelitian}

Penelitian ini bertujuan untuk mendapatkan modul bangunan yang efisien ketika dipadukan dengan rak - rak tanaman dengan berbagai macam ukuran. Hal tersebut juga mendukung terciptanya ruang pergerakan yang efisien di dalam bangunan. Untuk mencapai tujuan tersebut, penelitian ini merumuskan pertanyaan penelitian bagaimana menciptakan desain modul yang efisien untuk bangunan edu agrowisata?, dan bagaimana menciptakan ruang penempatan rak tanaman yang efisien dengan sirkulasi pengguna bangunan?

\section{DISKUSI DAN HASIL}

\section{Data - Data Tapak}

Tapak terletak di Jl. Sultan Iskandar Muda dengan lebar jalan dimukanya 15 meter dengan 2 jalur. Memiliki spesifikasi luas tapak 8700m2, KDB (50\%) 4350m2, KLB (1.2) 17400m2, KB 4, $\mathrm{KDH}(30 \%) 2610 \mathrm{~m} 2, \mathrm{KTB}(50 \%) 4350 \mathrm{~m} 2$

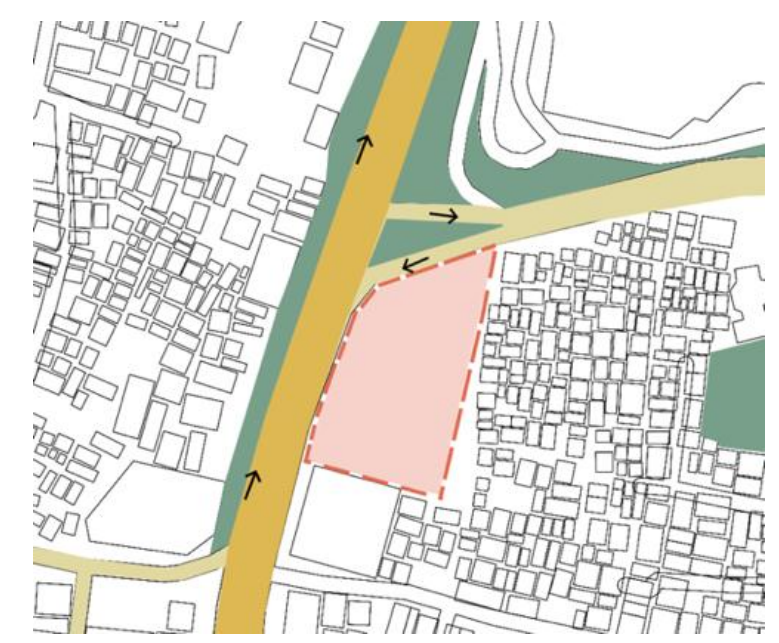

Gambar 1. Data Tapak

Sumber: Olahan Pribadi 2018

\section{Analisis}

Analisis diawali dari memilih tanaman yang dapat ditanam dalam sistem tanam hidroponik. Ada beberapa sistem tanam hidroponik, diantaranya adalah Nutrient Film Techniques, Aeroponik, Drip, Kultur, dan Ebb \& Flow. Kemudian berikut jenis tanaman yang dapat diterapkan dengan sistem hidroponik;

Tabel 1. Jenis Tanaman

\begin{tabular}{|l|l|l|}
\hline $\begin{array}{l}\text { Jenis } \\
\text { Tanaman }\end{array}$ & $\begin{array}{l}\text { Jarak } \\
\text { Tanam } \\
\text { (cm) }\end{array}$ & $\begin{array}{l}\text { Waktu Panen } \\
\text { (Hari) }\end{array}$ \\
\hline Pokcay & 15 & $40-45$ \\
\hline Selada Hijau & 15 & $30-40$ \\
\hline Brokoli & 20 & $30-40$ \\
\hline Bayam & 20 & $25-30$ \\
\hline Sawi & 20 & $40-60$ \\
\hline Kemangi & 20 & 50 \\
\hline Seledri & 15 & $30-40$ \\
\hline
\end{tabular}

Sumber: Olahan Pribadi 2018

Analisis desain modul diawali dari rak tanaman yang akan dimasukkan ke dalam bangunan 
agar penggunaan modul yang diterapkan efisien. Dimulai dari rak pertama dengan ukuran $(0.5$ x $0.5 \times 2.3 \mathrm{~m}$ ). Kapasitas rak tanam ini adalah 140 tanaman. Rak berikut menggunakan sistem tanam aeroponik. Kelebihan dari rak ini enteng dan tidak terlalu besar, jadi mudah dipindah pindahkan. Panen juga dapat dilakukan tanpa membutuhkan alat bantuan. Rak tanam ini hanya dapat untuk menanam tanaman jenis bawang - bawangan dan golongan umbi.

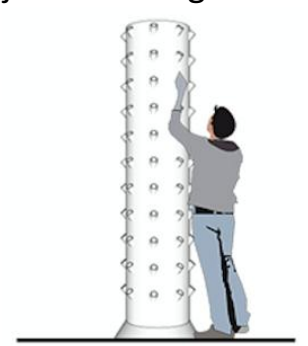

Gambar 2. Rak Tipe $1(0.5 \times 0.5 \times 2.3 \mathrm{~m})$

Sumber: Olahan Pribadi 2018

Kemudian berikut adalah tipe rak untuk area edukasi dengan ukuran $(4 \times 1.85 \times 3 \mathrm{~m})$. Rak ini menggunakan sistem tanam Nutirnet Film Techniques dengan daya tampung sebanyak 380 tanaman. Sistem tanam ini efektif untuk tanaman kecil. Massa Edukasi mempunyai kemampuan produksi terkecil karena sebagian besar areanya digunakan untuk kepentingan edukasi.

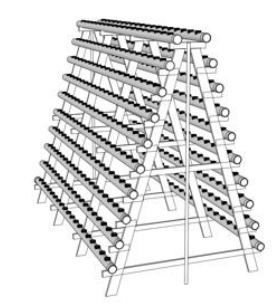

Gambar 3. Rak Tipe $2(4 \times 1.85 \times 3 \mathrm{~m})$

Sumber: Olahan Pribadi 2018

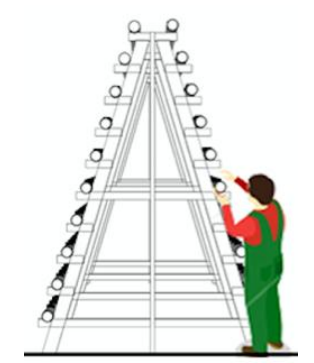

Gambar 5. Tampak Depan Rak Tipe 2

Sumber: Olahan Pribadi 2018

Rak ini berukuran $(2 \times 1.2 \times 6 \mathrm{~m})$. Rak ini diletakkan di massa produksi, dimana tanaman ini dapat ditanam secara massal. Rak ini memiliki kapasitas tanaman paling tinggi (104 tanaman/baris), lalu ketinggian bisa diatur sesuai dengan tinggi plafond. Ketinggian rak juga dapat disesuaikan terhadap tinggi ruang. Dengan demikian, penggunaan ruang untuk tipe rak tanam ini tidak membutuhkan ruang yang besar namun hanya perlu sistem pengaturan suhu untuk hasil penanaman yang maksimal. 


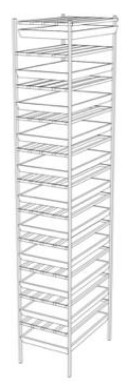

Gambar 6. Rak Tipe $3(2 \times 1.2 \times 6 \mathrm{~m})$

Sumber: Olahan Pribadi 2018

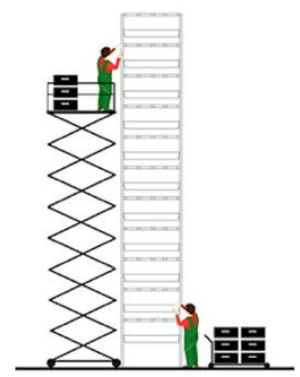

Gambar 7. Tampak Depan Rak Tipe 3

Sumber: Olahan Pribadi 2018

Rak ini berukuran $(2 \times 2 \times 4 \mathrm{~m})$, rak ini memiliki kapasitas tanam 600 tanaman dengan sistem tanam aeroponik. Rak tanam ini memiliki kapasitas tanam terbanyak. Dengan demikian, penggunaan ruang untuk tipe rak tanam ini tidak membutuhkan ruang yang cukup besar karena ukurannya, dan ruang untuk sirkulasi manusia untuk kebutuhan panen tanaman.

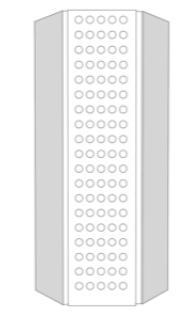

Gambar 8. Tipe Rak $4(2 \times 2 \times 4 \mathrm{~m})$

Sumber: Olahan Pribadi 2018

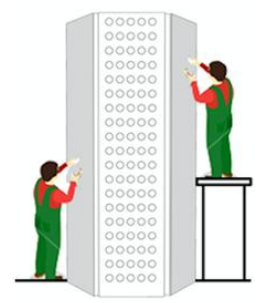

Gambar 9. Tampak Depan Tipe Rak 4

Sumber: Olahan Pribadi 2018

Setelah mengetahui ukuran rak yang akan dimasukkan ke dalam tapak, rak disesuaikan dengan modul yang akan dipakai. Setelah melakukan kalkukasi, ukuran modul juga disesuaikan dengan kebutuhan parkir kendaran di basemen. Lalu, sebagai kesimpulan modul yang paling efisien yang digunakan pada bangunan adalah $8 \times 8 \mathrm{~m}$ dan $12 \times 8 \mathrm{~m}$, serta $12 \times 12 \mathrm{~m}$. 


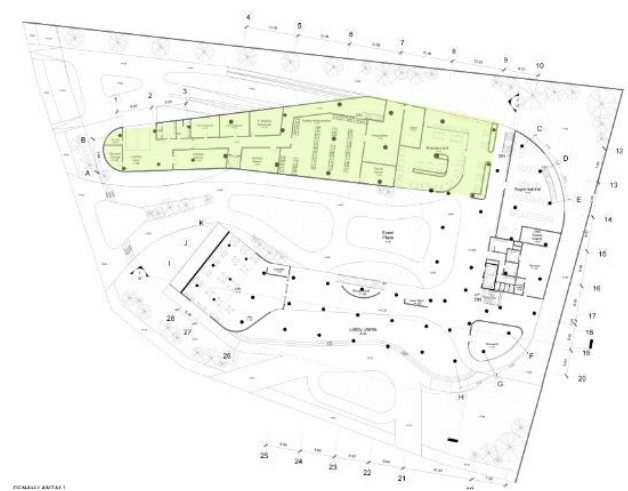

Gambar 10. Modul Bangunan 12x12m

Sumber: Olahan Pribadi 2018

Penerapan modul pada area produksi menerapkan modul $12 \times 12 \mathrm{~m}$ dengan tujuan agar pergerakkan pada area produksi dapat lebih leluasa dengan memuat rak yang lebih banyak untuk memaksimalkan kuantitas hasil produksi.

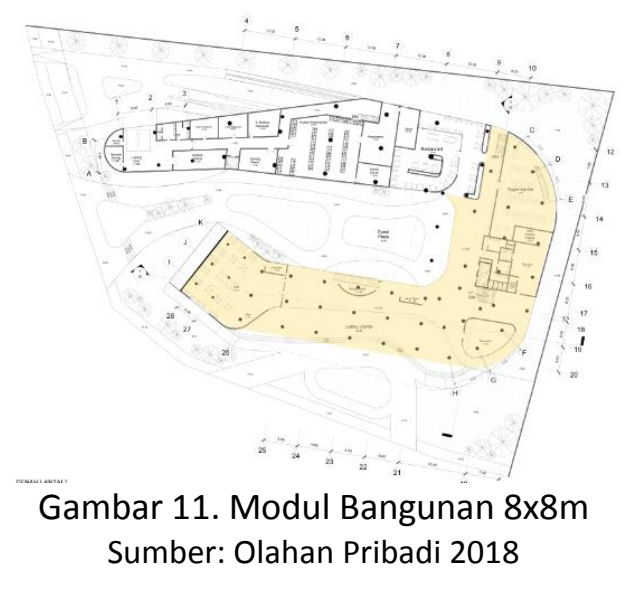

Kemudian, pada area lainnya menerapkan modul $8 \times 8 \mathrm{~m}$ sehubungan dengan ukuran rak yang paling lebar $4 \mathrm{~m}$, dan sisa ruang dapat digunakan sebagai area sirkulasi untuk pengunjung dan kegiatan petik dan tanam pada waktu panen. Kemudian ukuran modul $8 \times 8 \mathrm{~m}$ juga memperhitungkan luas efisien untuk area parkir mobil.

\section{KESIMPULAN DAN SARAN}

Pada akhirnya untuk mendapatkan modul yang efisien dengan ukuran $8 \times 8 \mathrm{~m} ; 12 \times 8 \mathrm{~m}$; dan $12 \times 12 \mathrm{~m}$. Modul tersebut dihasilkan dari beberapa tipe rak yakni ada 4 tipe rak, yakni tipe rak 1 $(0.5 \times 0.5 \times 2.3 \mathrm{~m})$; tipe rak $2(4 \times 1.85 \times 3 \mathrm{~m})$; tipe rak $3(2 \times 1.2 \times 6 \mathrm{~m})$; tipe rak $4(2 \times 2 \times 4 \mathrm{~m})$.

Perlu adanya analisis terhadap penggunaan rak dan aktifitas yang terjadi di sekitarnya. Kemudian setelah mendapatkan perhitungan yang pas, akan tercipta hitungan modul yang pas sehingga dapat terjadi penggunaan ruang yang efisien dengan pergerakan sirkulasi yang pas sehingga bangunan dapat digunakan dengan nyaman.

\section{REFERENSI}

Ching, Francis D. K. (2000). Arsitektur: Bentuk, Ruang dan Tatanan. Jakarta: Erlangga Specht, Jan. (2014). Architectural Tourism: Building for Urban Travel Destinations. New York: Spinger

https://jakarta.bps.go.id/backend/pdf_publikkasi/Statistik-Transportasi-DKI-Jakarta-2015.pdf http://www.kemenpar.go.id/userfiles/LAKIP\%20DEPUTI\%20BPDIP\%20 